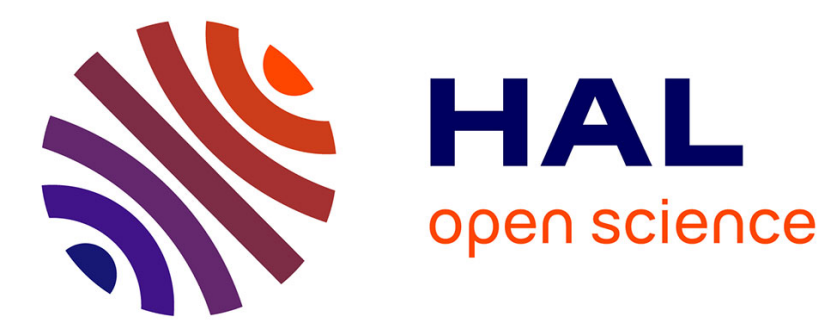

\title{
Habitat continuity effects on gradients of fish biomass across marine protected area boundaries
}

\author{
Aitor Forcada, Just T. Bayle, Carlos Valle, Pablo Sánchez-Jerez
}

\section{To cite this version:}

Aitor Forcada, Just T. Bayle, Carlos Valle, Pablo Sánchez-Jerez. Habitat continuity effects on gradients of fish biomass across marine protected area boundaries. Marine Environmental Research, 2008, 66 (5), pp.536. 10.1016/j.marenvres.2008.08.003 . hal-00501979

\section{HAL Id: hal-00501979 \\ https://hal.science/hal-00501979}

Submitted on 13 Jul 2010

HAL is a multi-disciplinary open access archive for the deposit and dissemination of scientific research documents, whether they are published or not. The documents may come from teaching and research institutions in France or abroad, or from public or private research centers.
L'archive ouverte pluridisciplinaire HAL, est destinée au dépôt et à la diffusion de documents scientifiques de niveau recherche, publiés ou non, émanant des établissements d'enseignement et de recherche français ou étrangers, des laboratoires publics ou privés. 


\section{Accepted Manuscript}

Habitat continuity effects on gradients of fish biomass across marine protected area boundaries

Aitor Forcada, Just T. Bayle, Carlos Valle, Pablo Sánchez-Jerez

PII:

S0141-1136(08)00199-2

DOI:

10.1016/j.marenvres.2008.08.003

Reference:

MERE 3281

To appear in:

Marine Environmental Research

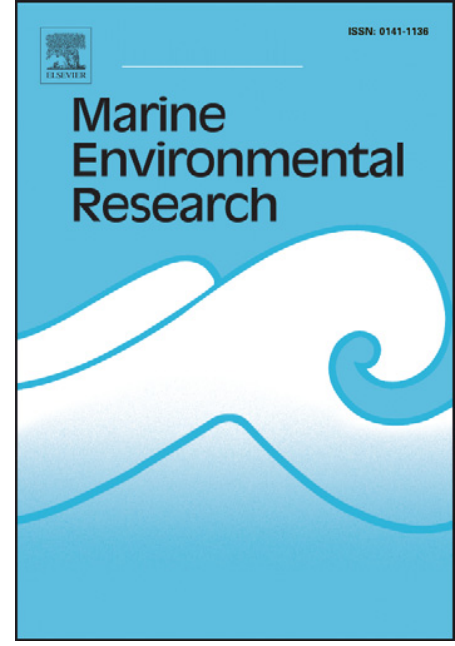

Received Date: $\quad 23$ May 2008

Revised Date: $\quad 11$ August 2008

Accepted Date: $\quad 12$ August 2008

Please cite this article as: Forcada, A., Bayle, J.T., Valle, C., Sánchez-Jerez,P., Habitat continuity effects on gradients of fish biomass across marine protected area boundaries, Marine Environmental Research (2008), doi: 10.1016/ j.marenvres.2008.08.003

This is a PDF file of an unedited manuscript that has been accepted for publication. As a service to our customers we are providing this early version of the manuscript. The manuscript will undergo copyediting, typesetting, and review of the resulting proof before it is published in its final form. Please note that during the production process errors may be discovered which could affect the content, and all legal disclaimers that apply to the journal pertain. 
1 Habitat continuity effects on gradients of fish biomass across marine

2 protected area boundaries.

3 Aitor FORCADA*, Just T. BAYLE, Carlos VALLE, Pablo SÁNCHEZ-JEREZ.

4 Unidad de Biología Marina, Departamento de Ciencias del Mar y Biología Aplicada,

5 Universidad de Alicante. POB 99, E-03080 Alicante, Spain.

6 *Corresponding author. E-mail: forcada@ua.es; Tel.: +34 965903400 Ext. 2916; Fax:

$7+34965909897$. 
8 ABSTRACT

Marine Protected Areas (MPAs) could be useful as fisheries management tools

10 for the exportation of pelagic eggs, larvae and adult fish. A decreasing gradient of fish

11 biomass across MPAs boundary may indicate export. We determine whether gradients

12 of decreasing biomass of fish assemblage occurred in Tabarca Marine Reserve over two

13 habitats with different continuity across the boundaries, to test if the patchy nature of

14 the marine environment might act as a barrier for the fish export. In general, significant

15 decreasing gradients in total fish biomass and biomass of some species were observed

16 on $P$. oceanica and rocky substrates, independently of their different continuity through

17 the reserve boundaries. Changes in the multivariate structure of the fish assemblage

18 were correlated with the distance from integral reserve. All of these results support the

19 hypothesis that the exportation of adult fish from Tabarca Marine Reserve occurs, and

20 this process may influence the surrounding fished areas.

21 Keywods: marine protected areas, fish, spillover, habitat continuity, visual census,

22 fisheries management. 


\section{INTRODUCTION}

In recent years, most coastal fish resources have been overexploited (Castilla, 2000), raising doubts about the long-term sustainability of certain fisheries (Pauly et al., 2002; Worm et al., 2006). In addition, fish habitats have also been strongly altered by widely used impacting fishing gears (trawls, dredges, ...) resulting in reduced seabed complexity and removal of macrobenthic organisms that provide shelter for others (Sumaila et al., 2000). The poor effectiveness of conventional fisheries management has led to increased interest among marine resource managers in marine protected areas (MPAs) (Bohnsack, 1998; Caddy, 2000), because they are considered a potential means of enhancing the long-term sustainability of many fisheries (Gell and Roberts, 2003; Sobel and Dahlgren, 2004; Ramos-Esplá et al., 2004). However, while the use of MPAs for this purpose is becoming popular, their ability to restock the fishing areas surrounding MPAs is also controversial (Willis et al., 2003; Hilborn et al., 2004; Sale et al., 2005).

A number of studies have explored the effect of the cessation of fishing within MPAs and in general, abundance, biomass and mean size of exploited fish populations are higher within protected areas than in nearby non-reserve areas (see Halpern, 2003 for review). However, to be useful as fisheries management tools, MPAs need to affect outside fished areas in a positive manner (Russ, 2002; Gell and Roberts, 2003). To benefit fisheries, MPAs are predicted to support adjacent fisheries through two mechanisms: net emigration of adults and juveniles across borders, termed "spillover", and with the increased production and exportation of pelagic eggs and larvae (Rowley, 1994; Kaunda-Arara and Rose, 2004; Abesamis and Russ, 2005). 
A decreasing gradient of fish biomass across MPAs boundaries, from high inside to low outside, may indicate spillover (Rakitin and Kramer, 1996). Net emigration of adult fish from the MPA, combined with fishing mortality outside, may produce such a decreasing pattern of biomass (Rakitin and Kramer, 1996; Abesamis and Russ, 2005). Protection increases the abundance of the most targeted species by fisheries (e.g. big serranids and big sparids), favouring changes in the fish assemblage structure (OjedaMartinez et al., 2007). Therefore, if spillover occurs the structure of fish assemblage will change related with the distance from the MPA. Reporting MPA effectiveness only by total or by individual species biomass is important but not sufficient from an ecosystem-based perspective, being necessary to study the changes in the fish assemblage structure to evaluate precisely the recovery effects of protection. Decreasing gradients of fish biomass across MPA boundaries were observed in a number of studies in tropical and temperate regions, using underwater visual census (Russ and Alcala, 1996; Ashworth and Ormond, 2005), catch rates (Kaunda-Arara and Rose, 2004; Goñi et al., 2006) or both (Rakitin and Kramer, 1996; Russ et al., 2003, 2004; Abesamis and Russ, 2005). However, these studies did not account for differences in habitat between the reserve and the fished sites. Therefore, the patterns could have been due to spillover or to habitat differences, which affect fish density (Chapman and Kramer, 1999;

Abesamis et al., 2006). Nevertheless, it is still unclear whether a decreasing gradient of fish biomass across a reserve boundary indicates spillover. Many environmental factors may explain spatial and temporal variability of littoral fish local assemblages. Habitat structure in the form of habitat complexity and/or heterogeneity (McCoy and Bell, 1991), and also variations in depth (Bell, 1983), are often related to fish population size and assemblage structure (Ruitton et al., 2000; García-Charton and Pérez-Ruzafa, 2001; Letourneur et al., 2003). Thus, gradients of decreasing biomass across MPAs 
71 boundaries may reflect better habitat characteristics inside than outside reserves, rather

72 than effects of protection from fishing in the reserve. Disentangling the effects due to

73 habitat structure will avoid "ecological confounding" in the interpretation of results

74 (Hurlbert, 1984; Underwood, 1997), as well as increase the chance of correctly interpreting the observed spatial and temporal heterogeneity of fish populations due to protection.

In addition, if gradients of decreasing biomass away from MPAs are due to spillover, the availability of a continuous habitat suitable for fish adjacent to reserves may have been important in promoting the net emigration of some fish from the reserves. Spillover benefits are more likely if reserves and their immediate surroundings occur in relatively homogeneous habitat (Chapman and Kramer, 2000; McClanahan and Mangi, 2000; Kaunda-Arara and Rose, 2004), because many fishes are habitat specific and are reluctant to disperse across "foreign" habitats (Chapman and Kramer, 2000). For this reason, spillover will also be influenced by the habitat bordering a reserve (Rowley, 1994).

The ideas of protecting breeding stocks, improving recruitment to neighbouring areas, and restocking marine species of commercial interest, were the most important initial goals of the creation of Tabarca Marine Reserve (Ramos-Esplá, 1985). This MPA was established in 1986, and it has already yielded a large background of data showing the presence of higher biomass inside. Overall fish abundance and biomass were respectively $92 \%$ and $317 \%$ higher in Tabarca Marine Reserve with reference to control fished areas (Forcada, 2005). Moreover, different traditional fishing grounds are distributed around Tabarca Marine Reserve, which are mainly used by the artisanal fleet 
causing a concentration of fishing effort close to the reserve boundaries (Goñi et al., in press).

The main objective of this work was to assess spillover examining gradients of fish biomass across Tabarca Marine Reserve boundaries. As a second objective, with the aim to test if the patchy nature of the marine environment might act as a barrier for the movement of fish, we investigated the gradients over two habitats: Posidonia oceanica seagrass meadow (continuous through reserve boundaries) and rocky substrate (discontinuous through reserve boundaries). Furthermore, we explored the relationship between the fish assemblage and habitat structure, as an environmental factor likely to account for an important part of the variability along the gradient. We statistically control the effects of habitat correlates of fish assemblage to test the hypothesis that gradients are due to reserve protection rather than measured habitat differences. Finally, changes in the structure of the fish assemblage were assessed at different distances from the integral reserve to test the effect of spillover.

\section{MATERIALS AND METHODS}

\subsection{AREA DESCRIPTIONS}

This study was carried out during June-July in 2005 and 2006 in Tabarca Marine

Reserve (South-western Mediterranean Sea, Spain). Tabarca Marine Reserve was created in 1986 and is 1400 ha. This MPA is zoned in three management zones with different levels of protection (Ramos-Esplá, 1985; Fig. 1): (I) the Integral reserve area (100 ha), where all human uses and activities are prohibited, except the scientific research; (II) the Buffer area (630 ha), in which some selective fishing methods are allowed; and (III) the Transitional area (670 ha), in which a number of activities are permitted (selective fishing techniques, swimming, SCUBA diving, mooring of yachts). 
118 The main habitat, Posidonia oceanica meadows, is highly extended outside the borders

119 in a continuous way, furthermore rocky bottoms also have a patchy distribution over the

120 area of study.

121

\subsection{STUDY DESIGN AND METHODS}

To test our hypothesis, 7 localities were positioned at increasing distances from the core of the integral reserve and with different protection status (4 inside the MPA and 3 in fished areas) (Fig. 1). In each locality, 3 sites were randomly located at a scale of 100s of metres. Finally, six random visual counts (replicates) separated by 10s of metres were done in each site. The surveys were carried out over one continuous habitat (Posidonia oceanica seagrass meadow) and another discontinuous (rocky substrate). To assess for the temporal consistency in the results, we repeated this sampling procedure two times, resulting in a total of 504 replicates in the data set.

Fish assemblage was sampled by means of underwater visual census techniques. The abundance and size (total length in classes of $2 \mathrm{~cm}$ ) of each fish species was recorded by a SCUBA diver within a $25 \times 5 \mathrm{~m}$ transect in rocky substrate, and a $50 \times 5 \mathrm{~m}$ transect in P. oceanica meadow as fish were more dispersed in this habitat (HarmelinVivien et al., 1985). This procedure is quite precise after a training period (Bell et al., 1985). Each observation was assigned to one of nine predetermined abundance classes (Harmelin, 1987), the limits of which coincide approximately with the terms of a base 2 geometric series. Geometric means of each fish abundance class were used for further calculations. This system of recording numbers, which is usual for fish censuses, leads to similar degrees of error over a wide range of abundances, and insures the homogeneity of variances when performing analyses with log-transformed data (Frontier, 1986). 
Habitat was described using substrate variables, distinguishing between vertical complexity (estimated as number of rocky boulders and verticality), horizontal heterogeneity (cover of different substrate) and depth (García-Charton and PérezRuzafa, 2001). After counting fish, the same observer covered the transect length in the opposite direction to count the number of rocky boulders classified by the size of their major length: small (major length: 50-100 cm), medium (major length: 100-200 cm), and large (major length: $>200 \mathrm{~cm}$ ). The observer completed measuring the minimum and maximum depth, and verticality (was estimated as the vertical distance between the deepest and the shallowest point inside each transect). Finally, habitat heterogeneity was estimated visually within each transect as the relative percentage cover of different substrate types: rock, sand and $P$. oceanica meadow. Because the location of each sampling site was randomly selected, its geographical position was denoted by means of a global positioning system (GPS). Subsequently for each site, distance from the centre of the integral reserve and distance from Tabarca Marine Reserve boundary were calculated by means of a geographic information system (GIS).

The seasonality is an important environmental variable on fish assemblage in temperate systems (Ansari et al., 1995; Magill and Sayer, 2002). For this reason, the surveys were done in the same season to reduce the natural variance between replicates thus providing better evidence of spatial patterns of distribution. The warm season is the most suitable period for visual counts in the Mediterranean, as fish communities are more diverse and stable during this period (Harmelin, 1987). Fish censuses were then performed during June and July, between 10:00-15:00 h, and with optimal seawater conditions of turbidity and swell.

\subsection{DATA ANALYSIS}


Fish assemblage structure was specified for each transect by total biomass. Individual weights of fish were estimated from published length-weight relationships (Valle et al., 2003). For each species we estimated its relative frequency of occurrence, separately for each habitat considered in the experimental design.

'Total reduced biomass' was also estimated by excluding from the calculations all pelagic species (Atherinidae, Centracanthidae, Pomacentridae and the Sparidae Boops boops and Oblada melanura). These species are often abundant and gregarious, and their high variability in spatial distribution may mask the effect of protection or habitat (Harmelin, 1987; Garcia-Charton et al., 2004). Species belonging to Gobiidae and Scorpaenidae are particularly cryptic or hidden and they require a sampling procedure specially adapted to their characteristics (Willis, 2001). For this reason, these species were not analysed and were also removed from the estimation of 'total reduced biomass'.

\section{Influence of habitat characteristics}

Linear regression was used to assess whether habitat variables (cover of different substrate types, number of rocky boulders, depth and verticality) were related with distance from integral reserve centre. An analysis of variance (ANOVA) of the regressions was performed in order to determine whether the association between the variables was statistically significant. Moreover, to explore the relationship between fish assemblage parameters — total reduced biomass and species biomass (lntransformed) — and the previous habitat structure descriptors (and their quadratic and cubic terms to explore the possible nonlinear relationship), multiple regression analyses 
were performed in the framework of generalized linear models (GLM) (McCullagh and Nelder, 1989; Chapman and Kramer, 1999; Letourneur et al., 2003; García-Charton et al., 2004). Fish variables were examined at a replicate level using multiple linear regressions. In each case, stepwise forward selection of variables was run, with the aim of maximizing the deviance reduction, followed by a stepwise backward elimination to prevent the loss of statistical significance of some variables due to the latter incorporation of new variables into the model. Before accepting any model, an analysis of residuals was performed to detect outliers with high influence on the models. We measured the leverage and the Cook statistic of each sampling unit (McCullagh and Nelder, 1989), so that any one with high values of leverage and influence was removed and the model refitted to insure consistency.

\section{Gradients of fish biomass}

Gradients of fish biomass across MPA boundaries were analysed using linear regressions. Average total reduced biomass and species biomass (ln-transformed) at each site were tested versus distance from integral reserve centre. Analyses were performed only on those non-pelagic taxa sufficiently frequent throughout the study, i.e. with a frequency of $\geq 10 \%$. These regressions were performed separately for two times sampled at each habitat. An ANOVA of the regressions was performed in order to determine whether the association between the variables was statistically significant.

To quantify the spatial variation after extracting the variability due to the influence of habitat variables, residuals of multiple linear regression analyses (defined as corrected biomass) were used as dependent variables repeating the linear regression with distance from integral reserve centre. This process was done in order to ensure that 
212 gradients were related to protection and not to differences in habitat features (Chapman

213 and Kramer, 1999; García-Charton et al., 2004).

\section{Changes in multivariate structure of fish assemblage}

We used multivariate techniques that are suited for ecological data because this

216 allowed the production of a diagnostic on the change of the entire fish assemblage.

217 Therefore, non-parametric approaches were selected by combining non-metric multidimensional scaling (MDS) and hierarchical cluster (Clarke, 1993; Clarke and Warwick, 2001), to assess differences in the biomass of the structure of the community within each locality, with regard to the different habitats and times considered by our sampling design.

With the aim of incorporating the influence of environmental variables in the assessment of the effect of distance from integral reserve over the fish assemblage, we perform BEST and LINKTREE routines included in PRIMER v6 software (Clarke and Gorley, 2006). A first appraisal of the relationships between species biomass and environment was provided by BEST, which was used to select the subset of environmental variables which best explains the multivariate pattern of the fish assemblage. In order to carry out a full search of all possible combinations of

229 environmental variables, BIO-ENV procedure was run using Spearman coefficient

230 (Kendall, 1970) as rank correlation method. Moreover, a global BEST match

231 permutation test (using 999 permutations) was applied to test agreement between fish

232 assemblage and the subset of environmental variables selected. The associated

233 Pearson's correlation coefficient of pairs of environmental variables was examined to 234 identify variables strongly correlated. All subsets of variables strongly collinear (with values $>0.95$ or $<-0.95$ ) were reduced to a single representative in the BEST run (Clarke 
and Warwick, 2001). In a second step, only the environmental variables selected by BEST were included as explicative variables in LINKTREE procedure (a nonparametric multivariate form of classification and regression trees; De'ath, 2002). This non-parametric multivariate discrimination technique constructs a hierarchical tree through successive dichotomies of the set of observations. Each division is characterised by one or more variables, and ranges of their values, that appear to be responsible for discriminating each different assemblage grouping. LINKTREE is capable of demonstrating that an environmental variable is important for internal assemblage structuring of one group of samples but not for another group (with similar values range).

The "similarity profile" permutation test (SIMPROF) (Clarke and Gorley, 2006), which test for significant evidence of multivariate structure among samples that have no pre-defined grouping, was combined with hierarchical cluster and LINKTREE to justify identification and interpretation of clusters. The significance level was conventionally taken as $5 \%$, and 1000 permutations were used to calculate the mean similarity profile, with 999 to generate the null distribution of the departure statistic, $\pi$.

For the overall multivariate testing technique, similarities among fish assemblage were calculated using the Bray-Curtis similarity index (Bray and Curtis, 1957) on the log-transformed biomass data by species. Censuses from P. oceanica meadow and from rocky substrate were computed together. For protection status, a dummy variable of ' 1 ' was assigned to transects inside the MPA, and ' 0 ' for those in fished areas. Again, for habitat factor, another dummy variable of ' 0 ' was assigned for transects over rocky substrate, and ' 1 ' for those carried out on $P$. oceanica meadow. These two dummy variables (called MPA and habitat respectively), distance from the 
260 integral reserve centre, and distance from MPA boundary were included in the

261 environmental data matrix with the substrate variables collected during the visual

262 census. Environmental variables similarity matrix used in the prior analysis was

263 calculated within localities using Normalised Euclidean distance (Clarke and Warwick, 264 2001).

\section{RESULTS}

\subsection{FISH ASSEMBLAGE}

During this study, a total of 47 fish species were observed (belonging to 16

families), of which 38 appeared in P. oceanica and 45 on rocky substrate (Appendix A).

The most representative family was Sparidae followed by Labridae, with 13 and 12 species respectively. Total biomass averaged $2213 \pm 307$ (SE, standard error) g $125 \mathrm{~m}^{-2}$ on $P$. oceanica, and $10225 \pm 1003$ (SE) g $125 \mathrm{~m}^{-2}$ in rocky substrate. Total reduced biomass — i.e. excluding from the summation pelagic and cryptic species — attained values of $1503 \pm 278$ (SE) and $8874 \pm 971$ (SE) g $125 \mathrm{~m}^{-2}$, in P. oceanica and rocky substrate respectively.

\subsection{INFLUENCE OF HABITAT STRUCTURE ON THE FISH ASSEMBLAGE} $p<0.05$ ), and number of small (Time $1: \mathrm{R}^{2}=0.405, p<0.01$; Time $2: \mathrm{R}^{2}=0.488, p<0.001$ ) and medium-sized (Time $1: \mathrm{R}^{2}=0.365, p<0.01$ ) rocky boulders, declined significantly across the reserve boundary. In addition, verticality increased significantly with distance

282 from integral reserve (Time $1: \mathrm{R}^{2}=0.591, p<0.001$; Time $2: \mathrm{R}^{2}=0.189, p<0.05$ ). On the 
other hand, on rocky substrate, a significant linear decrease of rock cover was obtained across the reserve boundary (Time $1: \mathrm{R}^{2}=0.293, p<0.05$ ), whereas seagrass cover showed the opposite trend (Time $1: \mathrm{R}^{2}=0.315, p<0.01$ ). Furthermore, medium-sized (Time $2: \mathrm{R}^{2}=0.310, p<0.01$ ) and large (Time $\left.2: \mathrm{R}^{2}=0.517, p<0.001\right)$ rocky boulders increased significantly with distance from integral reserve.

The parameters of fish assemblage responded to combinations of complexity and heterogeneity of habitat. The analyses of residuals confirm the goodness-of-fit of the models, so that no further reference will be given to these procedures. The regression model constructed on the observed values of total reduced biomass on P. oceanica, incorporated four habitat variables to explain $32.5 \%$ of the variation (Table 1). Biomass responded to variations in rock cover, minimum and maximum depth and number of small boulders. Similarly, on rocky substrate, the multiple regression analysis of reduced biomass accounted for $28.4 \%$ of the variation, but the model incorporated rock cover, verticality and number of large boulders (Table 1).

Significant models were obtained for 11 of the 12 most frequent non-pelagic species on $P$. oceanica, when exploring the relationship between their biomass and habitat variables (Table 1). The fitted models accounted for $1.9-16.2 \%$ of the observed variation in species biomasses, although the explained variance was substantial (>10\%) for only 5 species. Sand cover did not explain variation in any species biomass, while maximum and minimum depth were the habitat variables most included in the models. On rocky substrate, 20 non-pelagic species had a frequency of occurrence $\geq 10 \%$, and all of them showed significant models, but the proportion of variance explained exceed $10 \%$ only for 14 species (Table 1). In general, models incorporated more than two habitat variables and explained 2.3-29.3\% of total variation of species biomasses. 


\subsection{GRADIENTS OF FISH BIOMASS}

As the prior results exhibit, there was a significant spatial variation in habitat structure, and fish assemblage responded to changes in habitat heterogeneity and complexity. Therefore to try to distinguish between the effects of habitat and protection, we did the linear regressions using the values of original variables after correcting for the effect of habitat by using residuals of multiple regression analyses as dependent variables. By doing so, we found some changes compared with the analyses performed on raw data. In general, the slope of the linear regression and the proportion of variation explained by distance from integral reserve decreased after removing the effect of habitat. Moreover, after correcting for the effect of habitat, values of biomass of two species on $P$. oceanica, and four on rocky substrate, had lost the significance of the trend related with distance from integral reserve (Table 2). Additionally, two species on $P$. oceanica, and one on rocky substrate, did not maintain the expected pattern over time.

Corrected total reduced biomass decreased significantly across Tabarca boundaries on both $P$. oceanica and rocky substrates, and this pattern was observed over time (Fig. 2). Distance from integral reserve explained 26.1-38.8\% of total variation of corrected biomass on P. oceanica, and 24.7-67.3\% on rocky substrate (Table 2).

Concerning the most frequent non-pelagic species on P. oceanica, only 6 of them decreased significantly across Tabarca boundaries (Table 2). The gradient was significant in both sampling periods for Labrus merula (Fig. 3a) and Thalassoma pavo (Fig. 3c). However, it was significant only in one sampling time for Serranus scriba (Fig. 3e), Symphodus ocellatus (Fig. 3g), D. vulgaris (Fig. 3i) and S. salpa (Fig. 3k). On the other hand, on rocky substrate, corrected biomasses of 5 of the most frequent non- 
pelagic species had a significant decreasing trend (Table 2): Diplodus sargus (Fig. 3b) in two sampling times, and S. salpa (Fig. 3d), Symphodus ocellatus (Fig. 3f), E. marginatus (Fig. 3h) and Diplodus cervinus (Fig. 3j) in only one. On the contrary, corrected biomass of Symphodus rostratus (Fig. 31) increased across Tabarca boundaries, but it was significant only in one sampling time.

\subsection{SPATIAL VARIATION IN THE MULTIVARIATE STRUCTURE OF FISH}

\section{ASSEMBLAGE}

MDS clearly separated the two habitats sampled, except for localities 1 (during both times) and 3 (only during time 1) of $P$. oceanica, which had a similarity of $70 \%$ with the assemblage observed on rocky substrate (Fig. 4). SIMPROF test corroborated these results $(\pi=4.29, p<0.001)$. The pattern related with distance from integral reserve was observed only on rocky substrate. Fish assemblage in the integral reserve differed significantly $(\pi=1.11, p=0.015)$ from that censued on the other localities. Moreover, fish assemblages of the rest of localities were split significantly $(\pi=1.93, p<0.001)$ in two groups: the first one enclosed localities 2, 3 and 4, and the second included localities 5, 6 and 7. In the last group were also included the fish assemblage of the integral reserve of $P$. oceanica, which had a structure different to those observed in the other localities of seagrass.

The environmental variables, habitat, rock cover and maximum depth were strongly collinear with $P$. oceanica cover, number of small boulders and minimum depth respectively (Pearson's correlation coefficient $>0.95$ ). BEST results showed that the combination of substrate cover, number of medium-sized boulders, and distance from integral reserve was the most correlated with fish assemblage structure $(\rho=0.674$, $p<0.001$ ). The inclusion of these variables in LINKTREE analysis (Fig. 5) resulted that 
distance from integral reserve explained the differences found among localities of rocky substrate. On rocky habitat, substrate cover was also important in the differences found between the integral reserve and the localities 2, 3 and 4 .

\section{DISCUSSION}

Total reduced biomass of fish assemblage and biomass of some specific species exhibited a decreasing gradient across Tabarca Marine Reserve boundaries, which persisted even though the effects of the habitat structure were removed. Changes in the multivariate structure of the fish assemblage were also related with distance from integral reserve. The pattern was observed on both habitats studied, and persisted over time for total reduced biomass and some studied species.

The exploration of the relationship among fish assemblage parameters and environmental variables in this study corroborates that habitat structure is an important factor likely to explain the spatial distribution of Mediterranean fish assemblages. Whereas visual counts were performed on areas with habitat structure as comparable as possible, multiple linear regressions demonstrated that habitat characteristics, at the smallest spatial scale, influenced significantly the fish community parameters studied. Other studies also attribute a substantial part of the observed spatial variability in fish assemblages to habitat (Ruitton et al., 2000; García-Charton and Pérez-Ruzafa, 2001; Letourneur et al., 2003). Greater habitat heterogeneity and complexity result in a bigger variety of substrates and greater surface availability, therefore additional and a diversification of resources for individual fish are provided (food, refuge against predation or light, as well as resting or mating sites; García-Charton and Pérez-Ruzafa, 2001). We found that each of the habitat structure variables considered was significant in explaining the spatial distribution of the studied fish assemblage. This implies that all 
of them should be taken into account because only this approach may give the most comprehensive view of the fish assemblage-habitat relationship (Ruitton et al., 2000). In this sense, Mediterranean MPAs were usually established in zones that already harbour intrinsic structurally complex habitats (Ramos-Esplá et al., 2004), which favour the development of abundant fish fauna. Additionally, protection may also enhance the quality of habitat which is preserved inside MPAs from negative impacts (e.g. destructive fishing practices; Sumaila et al., 2000). In fact, the present study demonstrated that Tabarca Marine Reserve had some differences in habitat structure compared to surrounding areas. Most of the habitat variables that explain part of the variability of the fish assemblage had significant linear trends from inside to outside the marine reserve, and this influence was taken into account. The decrease in the number of significant gradients related to distance from integral reserve, when calculated after extraction of variation due to habitat, confirmed that habitat characteristics were, in some cases, more important than protection in explaining the pattern of the data. Note, however, that statistically controlling for habitat correlates may attribute effects of reserve protection to spuriously correlated habitat characteristics, increasing the potential for type II error when testing for significant effects of reserve protection (Chapman and Kramer, 1999). Our results indicating no significant effect of reserve status based on this approach should therefore be interpreted cautiously.

After extracting the effect of habitat, significant decreasing gradients of total fish biomass and most of the species studied were observed on $P$. oceanica and rocky substrate, and some of them were consistent over time. Changes in the structure of the fish assemblage were correlated with distance from integral reserve and not with protection status (inside-outside MPA). These gradual changes in fish assemblage related with distance from integral reserve, rather than a sudden change across the 
reserve boundary, indicate good evidence of biomass export. About the species that did not maintain the same pattern over time, it is part of the natural variability of the fish assemblage (Holbrook et al., 1994), which obliges to incorporate a suitable temporal replication in order to differentiate adequately the effects of protection. Net emigration of adult fish from Tabarca Marine Reserve combined with the high concentration of fishing effort around its boundaries (Goñi et al., in press) produce the observed decreasing patterns of biomass. These results corroborate the hypothesis of spillover (Rakitin and Kramer, 1996) around Tabarca Marine Reserve. On the contrary, the opposite pattern was obtained for S. rostratus, which increased significantly with distance from the centre of the Tabarca integral reserve. Similar results were found in other studies (Watson and Ormond, 1994; Kaunda-Arara and Rose, 2004; Ashworth and Ormond, 2005), where for some species greater abundance in fished areas have been observed, suggesting that this could be due to reduced competition or predation outside the reserve. Theoretically, some families and species might be expected to experience negative effects from reserves, because species interactions may also have important effects (Pinnegar et al., 2000; Jennings, 2001).

Although significant decreasing gradients has been detected in both habitats, we found some differences between the results obtained in $P$. oceanica meadow and on rocky substrate. Distance from integral reserve explained greater proportion of variance of total reduced biomass on rocky substrate than in P. oceanica meadow. Moreover, the multivariate structure of the fish assemblage showed a gradual change related with distance from integral reserve on rocky substrate, meanwhile over $P$. oceanica only the assemblage of the integral reserve was different to those of the other localities. These results suggest that, contrary to what we expected, evidence of spillover seem to be clearer on rocky substrate even though it has a big discontinuity between inside to 
outside Tabarca Marine Reserve. Although the multivariate structure of fish assemblage was significantly different between $P$. oceanica and rocky substrate, $80 \%$ of the species were observed at both habitats. The relative lack of specificity of most species for bottom features could be the result of the combination of a relatively wide home range and flexibility on resources use in general. Although, another likely explanation is that most of the target species (e.g. E. marginatus, S. umbra, D. cervinus, etc) seek shelter during daytime hours on rocky substrates, increasing their residence time in this habitat, hence responses to protection would be intrinsically stronger to detect on rocky substrates relative to $P$. oceanica meadows. In this sense, the diet and pattern of space occupation of species may vary depending on age (Harmelin-Vivien et al., 1989), resulting in morphological changes, learning, social rank, reproductive state and sex (in the case of sequential hermaphrodite species) (Forrester, 1991; McCormick, 1998). Furthermore, most fish species would be sufficiently flexible in their feeding and space requirements to adapt to resources available at each site and to avoid competing for them with conspecifics or individuals of other species, as suggested by a few studies in the Mediterranean Sea (Harmelin-Vivien et al., 1989; Jennings et al., 1997). Therefore, it can be suggested that movements of fish among rocky patches could occur easily through $P$. oceanica meadows which acts as a suitable path. It has been pointed out (Roberts, 2000) that habitat continuity through MPAs limits is important for biomass export to open fished areas. An extensive tagging study carried out in Apo Reserve (Chapman and Kramer, 2000) supports this assessment. When reserve boundaries are set at natural barriers where costs of moving increase, relocation across the boundaries should be reduced, and conversely, fish may readily move from reserves to fished areas when these areas are connected by continuous suitable habitat (Chapman and Kramer, 2000). However, this assumption does not seem to be useful for the fish assemblage 
associated to rocky patches located inside $P$. oceanica beds. Our results suggest that fish could move easily among rocky patches when they are located inside $P$. oceanica meadows. To obtain spillover effects, habitat continuity of rocky bottoms is not as important as their presence inside and outside the MPA, only if they are properly connected. Defining and understanding the mosaic of habitats and their connection within the ecosystem is critical. MPAs need to be viewed in the larger context of the entire ecosystem and their design needs to consider the habitat requirements and life histories of the species of interest, as well as the extent to which these habitats interact at larger spatial scales.

\section{CONCLUSIONS}

This study detected gradients of decreasing biomass of fish across the boundaries of Tabarca Marine Reserve, which continued even after removing the effects of the habitat structure. This pattern persisted over time for total reduced biomass and some studied species. Decreasing gradients appeared in both habitats studied, $P$. oceanica meadow and rocky substrate, and independently of their different continuity through the reserve boundaries. These gradients ultimately culminated in progressive change in the structure of fish assemblages, particularly on rocky substrate. All of these results support the hypothesis that the export of fish from Tabarca Marine Reserve occurs. This process should provide local benefits to the artisanal fleet which operates in fishing grounds just around Tabarca Marine Reserve, achieving the main objective of the creation of this MPA.

\section{ACKNOWLEDGMENTS}

We very much appreciate the help received from J. A. García-Charton during the data analysis. We wish to acknowledge the friendly cooperation of MPA guards, Club 
478 Náutico Santa Pola and the Secretaría General de Pesca Marítima. A. Forcada was

479 supported by FPI grant of the Generalitat Valenciana (CTBPRB/2003/146). Thanks to

480 the anonymous reviewers for their useful comments on the manuscript.

\section{REFERENCES}

Abesamis, R.A., Russ, G.R., 2005. Density-dependent spillover from a marine reserve: long-term evidence. Ecological Applications 15(5), 1798-1812.

Abesamis, R.A., Russ, G.R., Alcala, A.C., 2006. Gradients of abundance of fish across no-take marine reserve boundaries: evidence from Philippine coral reefs. Aquatic Conservation: Marine and Freshwater Ecosystems 16, 349-371.

Ansari, Z.A., Chatterji, A., Ingole, B.S., Sreepada, R.A., Rivonkar, C.U., Parulekar, A.H., 1995. Community structure and seasonal variation of an inshore demersal fish. Community at Goa, west cost of India. Estuarine, Coastal and Shelf Science 41, 593610.

Ashworth, J.S., Ormond, R.F.G., 2005. Effects of fishing pressure and trophic group on abundance and spillover across boundaries of a no-take zone. Biological Conservation 121, 333-344.

Bell, J.D., 1983. Effects of depth and marine reserve fishing restrictions on the structure of a rocky reef fish assemblage in the north-western Mediterranean Sea. Journal of Applied Ecology 20, 357-369.

Bell, J.D., Craik, G.J.S., Pollard, D.A., Russell, B.C., 1985. Estimating length frequency distributions of large reef fish underwater. Coral Reefs 4, 41-44. 
Bohnsack, J.A., 1998. Application of marine reserves to reef fisheries management. Australian Journal of Ecology 23, 298-304.

Bray, J.R., Curtis, J.T., 1957. An ordination of the upland forest communities of southern Wisconsin. Ecological Monographs 27, 325-349.

Caddy, J.F., 2000. A fisheries management perspective on marine protected areas in the Mediterranean. Environmental Conservation 27 (2), 98-103.

Castilla, J.C., 2000. Roles of experimental marine ecology in coastal management and conservation. Journal of Experimental Marine Biology and Ecology 250, 3-21.

Chapman, M.R., Kramer, D.L., 1999. Gradients in coral reef fish density and size across the Barbados Marine Reserve boundary: effects of reserve protection and habitat characteristics. Marine Ecology Progress Series 181, 81-96.

Chapman, M.R., Kramer, D.L., 2000. Movements of fishes within and among fringing coral reefs in Barbados. Environmental Biology of Fishes 57, 11-24.

Clarke, K.R., 1993. Non-parametric multivariate analyses of changes in community structure. Australian Journal of Ecology 18, 117-143.

Clarke, K.R., Gorley, R.N., 2006. PRIMER v6: User manual/Tutorial. PRIMER-E: Plymouth, UK.

Clarke, K.R., Warwick, R.M., 2001. Change in marine communities: an approach to statistical analysis and interpretation, 2nd edition. PRIMER-E: Plymouth, UK.

De'ath, G., 2002. Multivariate regression trees: a new technique for modeling speciesenvironment relationships. Ecology 83, 1105-1117. 
Forcada, A., 2005. Ictiofauna en reservas marinas: influencia de la estructura del hábitat, efecto de la protección y tamaño del área protegida. Instituto Alicantino de Cultura Juan Gil-Albert. Publicaciones de la Diputación de Alicante. Alicante, Spain.

Forrester, G.E., 1991. Social rank, individual size and group composition as determinants of food consumtion by humbug damselfish, Dascyllys aruanus. Animal Behaviour 42, 701-711.

Frontier, S., 1986. La méthode des cotations d'abondance appliquée aux pécheries artisanales, in: Fontier, S., (Eds.), Evaluation et optimisation des plans d'échantillonnage en écologie littorale. PIREN: ATP 9.82.65, CNRS, pp. 263-285.

García-Charton, J.A., Pérez Ruzafa, A., 2001. Spatial pattern and the habitat structure of a Mediterranean rocky reef fish local assemblage. Marine Biology 138, 917-934.

García-Charton, J.A., Pérez-Ruzafa, A., Sáanchez-Jerez, P., Bayle-Sempere, J.T., Reñones, O., Moreno, D., 2004. Multiscale spatial heterogeneity, habitat structure, and the effect of marine reserves on Western Mediterranean rocky reef fish assemblages. Marine Biology 144, 161-182.

Gell, F.R. Roberts, C.M., 2003. Benefits beyond boundaries: the fishery effects of marine reserves. TRENDS in Ecology and Evolution 18 (9), 448-455.

Goñi, R., Quetglas, A., Reñones, O., 2006. Spillover of spiny lobsters Palinurus elephas from a marine reserve to an adjoining fishery. Marine Ecology Progress Series 308, 207-219.

Goñi, R., Adlerstein, S., Alvarez-Berastegui, D., Forcada, A., Reñones, O., Criquet, G., Polti, S., Cadiou, G., Valle, C., Lenfant, P., Bonhomme, P., Perez-Ruzafa, A., 
Sánchez-Lizaso, J-L., García-Charton, J., Bernard, G., Stelzenmüller, V., Planes, S., (in press). Evidence of spillover from six Western Mediterranean marine protected areas measured from artisanal fisheries. Marine Ecology Progress Series doi:10.3354/meps07532.

Halpern, B.S., 2003. The impact of marine reserves: Do reserves work and does size matter? Ecological Applications 13, S117-S137.

Harmelin, J.G., 1987. Structure and variability of the ichthyofauna in a Mediterranean protected rocky area (National Park of Port-Cros, France). PSZNI: Marine Ecology $8,263-284$.

Harmelin-Vivien, M.L., Harmelin, J.G., Chauvet, C., Duval, C., Galzin, R., Lejeune, P., Barnabé, G., Blanc, F., Chevalier, R., Duclerc, J., Lasserre, G., 1985. Evaluation visuelle des peuplements et populations de poissons. Méthodes et problémes. Revue d'écologie (Terre Vie) 40, 467-539.

Harmelin-Vivien, M.L., Kaim-Malka, R.A., Ledoyer, M., Jacob-Abraham, S. S., 1989. Food partitioning among scorpaenid fishes in Mediterranean seagrass beds. Journal of Fish Biology 34, 715-734.

Hilborn, R., Stokes, K., Maguire, J-J., Smith, T., Botsford, L. W., Mangel, M., Orensanz, J., Parma, A., Rice, J., Bell, J., Cochrane, K. L., Garcia, S., Hall, S.J., Kirkwood, G.P., Sainsbury, K., Stefansson, G., Stefansson, G., Walters, C., 2004. When can marine reserves improve fisheries management? Ocean and Coastal Management 47, 197-205.

Holbrook, S.J., Kingsford, M.J., Schmitt, R.J., Stephens, J.J.S., 1994. Spatial patterns of marine reef fish assemblages. American Zoologist 34, 463-475. 
Hurlbert, S.H., 1984. Pseudoreplication and the Design of Ecological Field Experiments. Ecological Monographs 54(2), 187-211.

Jennings, S., 2001. Patterns and predictions of population recovery in marine reserves. Reviews in Fish Biology and Fisheries 10, 209-231.

Jennings, S., Reñones, O., Morales-Nin, B., Polunin, N.V.C., Moranta, J., Coll, J., 1997. Spatial variation in the $\mathrm{N}^{15}$ and $\mathrm{C}^{13}$ stable isotope composition of plants, invertebrates and fishes on Mediterranean reefs: implications for the study of trophic pathways. Marine Ecology Progress Series 146, 109-116.

Kaunda-Arara, B., Rose, G.A., 2004. Effects of marine reef National Parks on fishery CPUE in coastal Kenya. Biological Conservation 118, 1-13.

Kendall, M.G., 1970. Rank correlation methods. Griffin, London.

Letourneu, Y., Ruitton, S., Sartoretto, S., 2003. Environmental and benthic habitat factors structuring the spatial distribution of a summer infralittoral fish assemblage in the north-western Mediterranean Sea. Journal of Marine Biologial Association of the United Kingdom 83, 193-204.

Magill, S.H., Sayer, M.D.J., 2002. Seasonal and interannual variation in fish assemblages of northern temperate rocky subtidal habitats. Journal of Fish Biology 61, 1198-1216.

McClanahan, T.R., Mangi, S., 2000. Spillover of exploitable fishes from a marine park and its effect on the adjacent fishery. Ecological Application 10(6), 1792-1805. 
McCormick, M.I., 1998. Ontogeny of diet shifts by a microcarnivorous fish, Cheilodactylus spectabilis: relationship between feeding mechanics, microhabitat selection and growth. Marine Biology 132, 9-20.

McCoy, E., Bell, S.S., 1991. Habitat structure: the evolution and diversification of a complex topic, in: Bell, S.S., McCoy, E.D., Mushinsky, H. R. (Eds.), Habitat Structure: the Physical Arrangement of Objects in Space. Chapman and Hall, New York, pp. 3-27.

McCullagh, P., Nelder, J.A., Generalized Linear Models. Chapman and Hall, New York.

Ojeda-Martinez, C., Bayle-Sempere, J.T., Sánchez-Jerez, P., Forcada, A., Valle, C., 2007. Detecting conservation benefits in spatially protected fish populations with meta-analysis of long-term monitoring data. Marine Biology 151, 1153-1161.

Pauly, D., Christensen, V., Guénette, S., Pitcher, T.J., Sumaila, U.R., Walters, C.J., Watson, R., Zeller, D., 2002. Towards sustainability in world fisheries. Nature 418, 689-695.

Pinnegar, J.K., Polunin, N.V.C., Francour, P., Badalamenti, F., Chemello, R., HarmelinVivien, M., Hereu, B., Milazzo, M., Zabala, M., D’Anna, G., Pipitone, C., 2000.

Trophic cascades in benthic marine ecosystems: lessons for fisheries and protectedarea management. Environmental Conservation 27, 179-200.

Rakitin, A., Kramer, D.L., 1996. Effect of a marine reserve on the distribution of coral reef fishes in Barbados. Marine Ecology Progress Series 131, 97-113. 
606

607

608

609

610

611

612

613

614

615

616

Ramos-Esplá, A.A., 1985. La Reserva Marina de la Isla Plana o Nueva Tabarca (Alicante). Publicación de la Universidad de Alicante-Ayuntamiento de Alicante, Alicante.

Ramos-Esplá, A.A., Valle-Pérez, C., Bayle-Sempere, J.T., Sánchez-Lizaso, J.L., 2004. Áreas Marinas Protegidas como herramientas de Gestión Pesquera en el Mediterráneo (Area COPEMED). Serie Informes y Estudios COPEMED nº 11.

Roberts, C.M., 2000. Selecting marine reserve locations: optimality versus opportunism. Bulletin of Marine Science 66(3), 581-592.

Rowley, R.J., 1994. Marine reserves in fisheries management. Aquatic Conservation: Marine and Freshwater Ecosystems 4, 233-254.

Ruitton, S., Francour, P., Boudouresque, C.F., 2000. Relationships between algae, benthic herbivorous invertebrates and fishes in rocky sublittoral communities of a temperate sea (Mediterranean). Estuarine, Coastal and Shelf Science 50, 217-230.

Russ, G.R., 2002. Yet another review of marine reserves as reef fishery management tools, in: Sale, P.F. (Ed.), Coral reef fishes, dynamics and diversity in a complex ecosystem. Academic Press, San Diego, California, pp. 421-443.

Russ, G.R. Alcala, A.C., 1996. Do marine reserves export adult fish biomass? Evidence from Apo Island, central Philippines. Marine Ecology Progress Series 132, 1-9.

Russ, G.R., Alcala, A.C., Maypa, A.P., 2003. Spillover from marine reserves: the case of Naso vlamingii at Apo Island, the Philippines. Marine Ecology Progress Series 264, 15-20. 
Sale, P.F., Cowen, R.K., Danilowicz, B.S., Jones, G.P., Kritzer, J.P., Lindeman, K.C., Planes, S., Polunin, N.V.C., Russ, G.R., Sadovy, Y.J., Steneck, R.S., 2005. Critical science gaps impede use of no-take fishery reserves. Trends in Ecology and Evolution 20, 74-80.

Sobel, J.A., Dahlgren, C.P., 2004. Marine reserves. A guide to science, design and use. Island Press, Washington D.C.

Sumaila, U.R., Guénette, S., Alder, J., Chuenpagdee, R., 2000. Addressing ecosystem effects of fishing using marine protected areas. ICES Journal of Marine Science 57, $752-760$.

Underwood, A.J., 1997. Experiments in ecology: their logical design and interpretation using analysis of variance. Cambridge, Cambridge University Press.

Valle, C., Bayle, J.T., Ramos, A.A., 2003. Weight-length relationships for selected fish species of the western Mediterranean Sea. Journal Application Ichthyology 19, 261262.

Watson, M., Ormond, R.F.G., 1994. Effect of an artisanal fishery on the fish and urchin populations of a Kenyan coral reef. Marine Ecology Progress Series 109, 115-129.

Willis, T.J., 2001. Visual census methods underestimate density and diversity of cryptic reef fishes. Journal of Fish Biology 59, 1408-1411.

Willis, T.J., Millar, R.B., Babcock, R.C., Tolimiery, N., 2003. Burdens of evidence and the benefits of marine reserves: putting Descartes before des horse? Environmental Conservation 30(2), 97-103. 


\section{ACCEPTED MANUSCRIPT}

648 Worm, B., Barbier, E. B., Beaumont, N., Duffi, E., Folke, C., Halpern, B. S., Jackson,

649 J.B.C., Lotze, H.K., Micheli, F., Palumbi, S.R., Sala, E., Selkoe, K.A., Stachowicz, J.

650 J., Watson, R., 2006. Impacts of Biodiversity Loss on Ocean Ecosystem Services.

$651 \quad$ Science $314,787-790$.

652 


\section{CAPTIONS}

Table 1. Results of multiple linear regression analysis of mean biomass (ln-transformed) (ln $\mathrm{g} / 125 \mathrm{~m}^{2}$ ) against habitat structure descriptors for total reduced biomass and the 12 and 20 species most frequent on $P$. oceanica meadow and on rocky substrate respectively. For full species names see Table 2.

Table 2. Linear regressions analyses for mean corrected biomass (residuals) versus distance (m) from integral reserve at each time of total reduced biomass and the 12 and 20 species most frequent on $P$. oceanica meadow and on rocky substrate respectively.

Figure 1. Tabarca Marine Reserve location, including limits and zonation (I: integral reserve area, II: buffer area, III: transitional area), and main habitat distribution. The position of the seven localities (L1: locality 1, L2: locality 2, .., L7: locality 7) sampled at each habitat (P: P. oceanica segrass meadow, R: rocky substrate) are also indicated.

Figure 2. Mean corrected total biomass (residuals) at each site as a function of distance from integral reserve centre (IR) on a) P. oceanica meadow and b) rocky substrate. A linear regression is showed for each time sampled when it was significant. Error bars indicate standard error.

Figure 3. Mean corrected biomass (residuals) at each site as a function of distance from integral reserve centre (IR), on $P$. oceanica meadow for a) Labrus merula, c) Thalassoma pavo, e) Serranus scriba, g) Symphodus ocellatus, i) Diplodus vulgaris and k) Sarpa salpa, and on rocky substrate for b) Diplodus sargus, d) Sarpa salpa, f) Symphodus ocellatus, h) Epinephelus marginatus, j) Diplodus cervinus and 1) Symphodus rostratus. A linear regression is showed for each time sampled when it was significant. Error bars indicate standard error. 
676 Figure 4. Two dimensional nMDS ordination of biomasses (log-transformed) of the 677 species observed at each locality at each time. Cluster results were superimposed, 678 grouping with similarity levels of $60 \%$ and $80 \%$. For each point, the first digit indicates 679 the time (1: time 1, 2: time 2) and the letter and number represent the locality (L1: 680 locality 1, L2: locality 2,.., L7: locality 7).

681 Figure 5. LINKTREE of biomass (log-transformed) of the species observed at each 682 locality within each time. The plot displays only those divisions for which SIMPROF 683 test was significant $(p<0.05)$. For each split the ANOSIM test statistic (R: rank 684 similarity index) is showed. B\%: absolute measure of group differences. For each 685 sample, the first digit indicates the time (1: time 1,2: time 2), the next letter the habitat 686 (R: Rocky substrate, P: P. oceanica meadow), and the last letter and number the locality 687 (L1: locality 1, L2: locality 2,.., L7: locality 7).

688 Appendix A. Mean total biomass \pm standard error $\left(\mathrm{g} / 125 \mathrm{~m}^{2}\right)$ and percentage of 689 frequency of occurrence (Freq.) of the species observed in P. oceanica meadow and 690 rocky substrate.

691 


\section{P. oceanica meadow}

P. ocenica meadow $2520.32525 .181^{\text {*20 }} 9.411$

C. julis

D. annularis $\begin{array}{llll}252 & 0.162 & 25.212 * * * & 2.593\end{array}$

\section{- $0.176-$}

D. vulgaris

L. merula

S. salpa

S. scriba

S. cantharus

S. ocellatus

S. rostratus

S. tinca

T. pavo

Rocky substrate

Reduced biomass $2510.284 \quad 20.481 * * * 6.961$

A. imberbis

C. julis

D. dentex

D. annularis

D. cervinus

D. puntazzo

D. sargas

D. vulgaris

E. marginatus

L. merula

S. salpa

S. umbra

S. scriba

S. cantharus

mediterra

S. ocellatus

S. roissali

S. rostratus

S. tinca

T. pavo

$\begin{array}{llll}251 & 0.123 & 12.723 * * * & 2.266\end{array}$

$\begin{array}{lllll}250 & 0.047 & 13.342 * * * & 9.078 & -0.076\end{array}$

$\begin{array}{llll}252 & 0.021 & 6.395 * & 0.675\end{array}$

$2520.125 \quad 18.888 * * * 1.709$

$\begin{array}{llll}252 & 0.101 & 15.141 * * * * & 1.550\end{array}$

$\begin{array}{llll}252 & 0.028 & 4.669 * & -0.527\end{array}$

$\begin{array}{lll}251 & 0.063 & 9.448 * * * \\ 2.932\end{array}$

$\begin{array}{lllll}252 & 0.019 & 5.927 * & 0.072\end{array}$

$252 \quad 0.025 \quad 4.153 * \quad 1.444$

$2490.156 \quad 46.928 * * * 0.193$

$2490.187 \quad 10.487 * * *-1.075$

$\begin{array}{lll}251 & 0.115 & 33.561 * * * \\ 2 & 3.078\end{array}$

$\begin{array}{llll}250 & 0.074 & 20.992 * * * *-0.183\end{array}$

$\begin{array}{lll}251 & 0.153 & 23.603 * * * \\ 2.597\end{array}$

$\begin{array}{llll}252 & 0.293 & 35.674 * * * & 4.709\end{array}$

$\begin{array}{llll}252 & 0.184 & 29.225 * * * & 0.611\end{array}$

$\begin{array}{llll}252 & 0.118 & 34.621 * * * & 3.506\end{array}$

$\begin{array}{llll}252 & 0.225 & 15.589 * * * & 3.141\end{array}$

$\begin{array}{lllll}252 & 0.168 & 26.423 * * * & 0.452\end{array}$

$\begin{array}{lll}252 & 0.148 & 15.570 * * * * \\ 3.748\end{array}$

$\begin{array}{llll}249 & 0.099 & 7.779 * * * & 4.240\end{array}$

$\begin{array}{lllll}248 & 0.141 & 14.548 * * * & 0.300\end{array}$

$\begin{array}{lllll}252 & 0.027 & 8.064 * * & 2.923\end{array}$

$\begin{array}{lll}252 & 0.111 & 16.732 * * * \\ 25 & 0.262\end{array}$

$\begin{array}{lllll}251 & 0.023 & 6.927 * * & 0.110\end{array}$

$\begin{array}{lllll}251 & 0.112 & 8.901 * * * & 0.722\end{array}$

$\begin{array}{llll}252 & 0.177 & 18.992 * * * & 3.369\end{array}$

$\begin{array}{llll}252 & 0.035 & 5.587 * * & 0.928\end{array}$

$\begin{array}{llll}250 & 0.074 & 20.917 * * * & 5.609\end{array}$

$$
\begin{array}{lllll}
- & - & - & 1.6 \mathrm{E}-6 & - \\
- & - & 4.3 \mathrm{E}-4-5.0 \mathrm{E}-6 & - \\
- & - & - & - & - \\
- & - & - & 2.1 \mathrm{E}-6 & - \\
- & - & - & -2.7 \mathrm{E}-6 & - \\
-7.4 \mathrm{E}-6 & - & -0.003 & 2.6 \mathrm{E}-5 & - \\
- & - & 3.6 \mathrm{E}-4 & - & - \\
- & - & - & 3.0 \mathrm{E}-6 & - \\
- & 0.017 & - & - & - \\
- & - & - & 3.9 \mathrm{E}-6 & - \\
- & 0.015 & - & - & -
\end{array}
$$

$-$

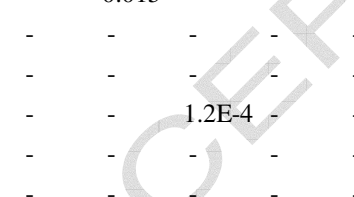

$-4.4 \mathrm{E}-6-0.097$

$-6.9 \mathrm{E}-7$

$-1.9 \mathrm{E}-6$$$
2520.245 \quad 14.597 * * * 0.730
$$

$1.6 \mathrm{E}-4-$

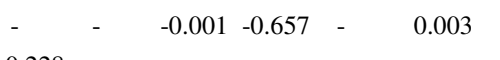

$\begin{array}{llllll}0.228 & - & - & - & - & - \\ -0.348 & - & - & - & - & -\end{array}$

0.002

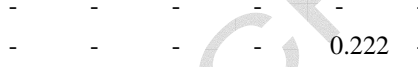

0.001

$-0.001$

$2.8 \mathrm{E}-4$

0.138

$-0.028$

693 Habitat structure descriptors: P.oce, P. oceanica cover; Rock, rock

695 larg.b, large boulders. Superscripts refer to quadratic and cubic terms. 
Table 2.

\begin{tabular}{|c|c|c|c|c|c|c|c|c|}
\hline \multirow{2}{*}{ Variables } & \multicolumn{4}{|c|}{ Time 1} & \multicolumn{4}{|c|}{ Time 2} \\
\hline & Const. & Slope & $\mathrm{R}^{2}$ & $F^{a}$ & Const. & Slope & $\mathrm{R}^{2}$ & $F^{a}$ \\
\hline \multicolumn{9}{|l|}{$\underline{\text { P. oceanica meadow }}$} \\
\hline Reduced biomass & 0.677 & -0.0001 & 0.261 & $6.733^{*}$ & 0.554 & -0.0002 & 0.388 & $12.090 * *$ \\
\hline Coris julis & -0.005 & $-1.1 \mathrm{E}-5$ & 0.003 & 0.059 & 0.187 & $-3.6 \mathrm{E}-5$ & 0.012 & 0.239 \\
\hline Diplodus annularis $^{\mathrm{d}}$ & 3.998 & $-9.8 \mathrm{E}-6$ & 0.001 & 0.023 & 4.290 & $-1.2 \mathrm{E}-4$ & 0.143 & 3.161 \\
\hline Diplodus sargus ${ }^{\mathrm{c}}$ & 0.036 & $5.8 \mathrm{E}-5$ & 0.026 & 0.517 & 0.068 & $-8.0 \mathrm{E}-5$ & 0.092 & 1.918 \\
\hline Diplodus vulgaris & 0.068 & $-2.7 \mathrm{E}-5$ & 0.004 & 0.079 & 0.826 & $-2.0 \mathrm{E}-4$ & 0.198 & $4.687 *$ \\
\hline Labrus merula & 0.261 & $-1.1 \mathrm{E}-4$ & 0.185 & $4.321^{*}$ & 1.436 & $-3.2 \mathrm{E}-4$ & 0.556 & $23.760 * * *$ \\
\hline Sarpa salpa ${ }^{\mathrm{b}}$ & 1.994 & $-4.7 \mathrm{E}-4$ & 0.376 & $11.464 * *$ & 0.826 & $-2.6 \mathrm{E}-4$ & 0.137 & 3.014 \\
\hline Serranus scriba ${ }^{\mathrm{b}}$ & 0.725 & $-2.0 \mathrm{E}-4$ & 0.284 & $7.519 *$ & 0.664 & $-1.5 \mathrm{E}-4$ & 0.151 & 3.371 \\
\hline Spondyliosoma cantharus $^{\mathrm{c}}$ & -0.201 & $1.2 \mathrm{E}-4$ & 0.156 & 3.524 & 0.018 & $-7.4 \mathrm{E}-5$ & 0.111 & 2.370 \\
\hline Symphodus ocellatus & -0.384 & $4.3 \mathrm{E}-6$ & 0.001 & 0.010 & 0.898 & $-1.3 \mathrm{E}-4$ & 0.178 & $4.119^{*}$ \\
\hline Symphodus rostratus & -0.034 & $-1.0 \mathrm{E}-5$ & 0.017 & 0.322 & 0.064 & $3.0 \mathrm{E}-6$ & 0.000 & 0.009 \\
\hline Symphodus tinca & -0.325 & $7.6 \mathrm{E}-6$ & 0.000 & 0.006 & 0.655 & $-9.3 \mathrm{E}-5$ & 0.044 & 0.878 \\
\hline Thalassoma pavo & 0.285 & $-8.5 \mathrm{E}-5$ & 0.318 & & 0.504 & $-1.2 \mathrm{E}-4$ & 0.595 & $27.930 * * *$ \\
\hline \multicolumn{9}{|l|}{ Rocky substrate } \\
\hline Reduced biomass & 0.746 & -0.0002 & 0.673 & $39.196 * * *$ & 0.079 & $-7.7 \mathrm{E}-5$ & 0.247 & $6.239^{*}$ \\
\hline Apogon imberbis ${ }^{\mathrm{c}}$ & 0.135 & $-3.3 \mathrm{E}-6$ & 0.000 & 0.004 & -0.073 & $-1.1 \mathrm{E}-5$ & 0.002 & 0.037 \\
\hline Coris julis & -0.157 & $2.9 \mathrm{E}-5$ & 0.017 & 0.331 & -0.015 & $2.5 \mathrm{E}-5$ & 0.019 & 0.365 \\
\hline Dentex dentex ${ }^{\mathrm{c}}$ & 0.839 & $-1.5 \mathrm{E}-4$ & 0.118 & 2.548 & -0.285 & $-1.5 \mathrm{E}-5$ & 0.004 & 0.086 \\
\hline Diplodus annularis ${ }^{\mathrm{c}}$ & -0.172 & $1.1 \mathrm{E}-4$ & 0.080 & 1.650 & -0.568 & $1.3 \mathrm{E}-4$ & 0.141 & 3.110 \\
\hline Diplodus cervinus & 0.474 & $-1.0 \mathrm{E}-4$ & 0.179 & $4.150^{*}$ & -0.175 & $2.1 \mathrm{E}-6$ & 0.000 & 0.001 \\
\hline Diplodus puntazzo & 0.749 & $-9.3 \mathrm{E}-5$ & 0.040 & 0.793 & -0.178 & $-9.9 \mathrm{E}-5$ & 0.051 & 1.020 \\
\hline Diplodus sargus & 1.210 & $-2.8 \mathrm{E}-4$ & 0.297 & $8.015^{*}$ & 0.270 & $-2.1 \mathrm{E}-4$ & 0.253 & $6.441 *$ \\
\hline Diplodus vulgaris & 0.395 & $-6.4 \mathrm{E}-5$ & 0.053 & 1.059 & -0.109 & $-3.2 \mathrm{E}-5$ & 0.011 & 0.202 \\
\hline Epinephelus margi & 0.547 & $-1.7 \mathrm{E}-4$ & 0.153 & 3.440 & 0.767 & $-2.6 \mathrm{E}-4$ & 0.309 & $8.485^{* *}$ \\
\hline Labrus merula & -0.161 & $-4.3 \mathrm{E}-5$ & 0.022 & 0.423 & 0.525 & $-8.0 \mathrm{E}-5$ & 0.059 & 1.192 \\
\hline Sarpa salpa & 2.236 & $-6.7 \mathrm{E}-4$ & 0.580 & $26.192 * * *$ & -0.876 & $2.0 \mathrm{E}-4$ & 0.080 & 1.642 \\
\hline Sciaena umbra & 0.068 & $-1.1 \mathrm{E}-4$ & 0.128 & 2.796 & 0.920 & $-2.1 \mathrm{E}-4$ & 0.122 & 2.629 \\
\hline Serranus scriba & 0.010 & $2.7 \mathrm{E}-5$ & 0.009 & 0.175 & -0.231 & $4.7 \mathrm{E}-5$ & 0.031 & 0.617 \\
\hline Spondyliosoma cantharus & 0.114 & $-1.0 \mathrm{E}-5$ & 0.002 & 0.038 & -0.215 & $4.5 \mathrm{E}-5$ & 0.067 & 1.355 \\
\hline Symphodus mediterraneus & 0.056 & $-1.3 \mathrm{E}-5$ & 0.005 & 0.103 & 0.051 & $-2.3 \mathrm{E}-5$ & 0.014 & 0.267 \\
\hline Symphodus ocellatus & -0.411 & $-1.1 \mathrm{E}-4$ & 0.187 & 4.372 & 0.653 & $3.6 \mathrm{E}-5$ & 0.016 & 0.306 \\
\hline Symphodus roissali & -0.074 & $1.0 \mathrm{E}-5$ & 0.004 & 0.074 & -0.001 & $1.4 \mathrm{E}-5$ & 0.004 & 0.086 \\
\hline Symphodus rostratus & 0.001 & $-4.4 \mathrm{E}-7$ & 0.000 & 0.000 & -0.411 & $1.3 \mathrm{E}-4$ & 0.381 & $11.697 * *$ \\
\hline Symphodus tinca & -0.004 & $-6.6 \mathrm{E}-5$ & 0.042 & 0.831 & 0.306 & $-3.8 \mathrm{E}-5$ & 0.017 & 0.330 \\
\hline Thalassoma pavo $^{\mathrm{c}}$ & 0.270 & $-8.8 \mathrm{E}-5$ & 0.096 & 2.026 & 0.350 & $-1.2 \mathrm{E}-4$ & 0.173 & 3.977 \\
\hline
\end{tabular}

$698{ }^{\mathrm{b}}$ Regression lost the significance in one time sampled after correcting for the effect of habitat.

$699{ }^{\mathrm{c}}$ Regression lost the significance in both times sampled after correcting for the effect of habitat.

$700 \quad{ }^{\mathrm{d}}$ Regression was done using mean biomass $\left(\mathrm{ln} \mathrm{g} / 125 \mathrm{~m}^{2}\right)$ because not significant relationship with habitat 701 was found. 


\begin{tabular}{|c|c|c|c|c|c|}
\hline \multirow{2}{*}{ Family } & \multirow{2}{*}{ Species } & \multicolumn{2}{|c|}{ P. oceanica meadow } & \multicolumn{2}{|c|}{ Rocky substrate } \\
\hline & & Biomass & Freq. & Biomass & Freq. \\
\hline Muraenidae & Muraena helena Linnaeus, 1758 & $3.14 \pm 3.14$ & 0.40 & $100.66 \pm 35.22$ & 4.76 \\
\hline \multirow[t]{6}{*}{ Serranidae } & Anthias anthias (Linnaeus, 1758) & $0.03 \pm 0.03$ & 0.40 & $0.09 \pm 0.09$ & 0.40 \\
\hline & Epinephelus costae Valenciennes, 1828 & $3.36 \pm 3.36$ & 0.40 & $26.91 \pm 10.75$ & 3.17 \\
\hline & Epinephelus marginatus (Lowe, 1834) & $187.03 \pm 119.46$ & 2.78 & $1339.01 \pm 431.57$ & 23.41 \\
\hline & Mycteroperca rubra (Bloch, 1793) & $8.37 \pm 8.37$ & 0.40 & $67.43 \pm 29.87$ & 3.17 \\
\hline & Serranus cabrilla (Linnaeus, 1758) & $0.20 \pm 0.15$ & 0.79 & $0.23 \pm 0.23$ & 0.40 \\
\hline & Serranus scriba Linnaeus, 1758 & $32.59 \pm 5.42$ & 71.03 & $80.52 \pm 5.23$ & 82.54 \\
\hline Moronidae & Dicentrarchus labrax Linnaeus, 1758 & - & 0.00 & $12.87 \pm 9.41$ & 1.98 \\
\hline Apogonidae & Apogon imberbis Lacepède, 1801 & - & 0.00 & $15.17 \pm 2.45$ & 30.95 \\
\hline Haemulidae & Pomadasys incisus (Bowdich, 1825) & - & 0.00 & $7.35 \pm 2.81$ & 3.97 \\
\hline Sciaenidae & Sciaena umbra Linnaeus, 1758 & $15.75 \pm 6.42$ & 5.95 & $320.02 \pm 61.07$ & 23.02 \\
\hline Mullidae & Mullus surmuletus Linnaeus, 1758 & $1.94 \pm 0.82$ & 7.54 & $1.53 \pm 0.64$ & 4.37 \\
\hline \multirow[t]{13}{*}{ Sparidae } & Boops boops (Linnaeus, 1758) & $218.05 \pm 35.21$ & 38.10 & $159.89 \pm 42.83$ & 11.90 \\
\hline & Dentex dentex (Linnaeus, 1758) & $110.84 \pm 44.67$ & 5.95 & $486.25 \pm 202.24$ & 11.90 \\
\hline & Diplodus annularis Rafinesque, 1810 & $81.97 \pm 5.33$ & 97.62 & $53.06 \pm 4.77$ & 64.68 \\
\hline & Diplodus cervinus Lowe, 1841 & $0.22 \pm 0.22$ & 0.40 & $45.43 \pm 10.58$ & 11.51 \\
\hline & Diplodus puntazzo, Cetti, 1789 & $5.31 \pm 2.50$ & 5.16 & $161.25 \pm 21.38$ & 38.10 \\
\hline & Diplodus sargus (Linnaeus, 1758) & $42.38 \pm 14.91$ & 23.41 & $585.50 \pm 63.32$ & 82.54 \\
\hline & Diplodus vulgaris (Geoffroy Saint-Hilaire, 1817) & $42.41 \pm 7.82$ & 47.22 & $803.38 \pm 139.87$ & 91.67 \\
\hline & Oblada melanura (Linnaeus, 1758) & $248.72 \pm 72.20$ & 62.30 & $672.94 \pm 171.12$ & 63.49 \\
\hline & Pagellus acarne (Risso, 1827) & - & 0.00 & $0.02 \pm 0.02$ & 0.40 \\
\hline & Pagrus pagrus (Linnaeus, 1758) & & 0.00 & $87.44 \pm 27.61$ & 7.94 \\
\hline & Sarpa salpa (Linnaeus, 1758) & $828.90 \pm 203.86$ & 32.14 & $4109.46 \pm 720.12$ & 63.89 \\
\hline & Sparus aurata Linnaeus, 1758 & $3.02 \pm 1.57$ & 1.59 & $39.41 \pm 13.38$ & 4.76 \\
\hline & Spondyliosoma cantharus (Linnaeus, 1758) & $4.44 \pm 0.80$ & 23.81 & $3.66 \pm 0.88$ & 10.71 \\
\hline \multirow{2}{*}{ Centracanthidae } & Spicara maena (Linnaeus, 1758) & $1.35 \pm 0.55$ & 4.37 & $6.89 \pm 6.82$ & 1.19 \\
\hline & Spicara smaris (Linnaeus, 1758) & $9.42 \pm 4.25$ & 5.16 & $35.30 \pm 16.32$ & 4.37 \\
\hline Pomacentridae & Chromis chromis (Linnaeus, 1758) & $166.21 \pm 33.59$ & 84.13 & $418.56 \pm 57.18$ & 85.71 \\
\hline \multirow[t]{12}{*}{ Labridae } & Coris julis (Linnaeus, 1758) & $37.40 \pm 2.16$ & 90.08 & $88.63 \pm 4.19$ & 94.84 \\
\hline & Labrus merula (Linnaeus, 1758) & $21.47 \pm 4.22$ & 17.06 & $91.21 \pm 14.45$ & 24.60 \\
\hline & Labrus viridis (Linnaeus, 1758) & $1.39 \pm 0.55$ & 3.57 & $2.76 \pm 1.26$ & 1.98 \\
\hline & Symphodus cinereus (Bonnaterre, 1788) & - & 0.00 & $0.05 \pm 0.04$ & 0.79 \\
\hline & Symphodus doderleini (Jordan, 1981) & $0.09 \pm 0.07$ & 0.79 & $0.23 \pm 0.11$ & 2.38 \\
\hline & Symphodus mediterraneus (Linnaeus, 1758) & $0.84 \pm 0.23$ & 6.35 & $4.99 \pm 0.91$ & 16.27 \\
\hline & Symphodus melanocercus (Risso, 1810) & $0.30 \pm 0.09$ & 5.95 & $1.25 \pm 0.30$ & 9.52 \\
\hline & Symphodus ocellatus Forsskal, 1775 & $6.90 \pm 0.83$ & 48.02 & $29.56 \pm 2.72$ & 57.94 \\
\hline & Symphodus roissali (Risso, 1810) & $0.39 \pm 0.13$ & 4.37 & $6.17 \pm 0.99$ & 25.00 \\
\hline & Symphodus rostratus (Bloch, 1797) & $1.05 \pm 0.22$ & 11.90 & $3.12 \pm 0.57$ & 15.48 \\
\hline & Symphodus tinca (Linnaeus, 1758) & $48.95 \pm 4.05$ & 72.22 & $228.80 \pm 15.81$ & 89.29 \\
\hline & Thalassoma pavo (Linnaeus, 1758) & $2.30 \pm 0.72$ & 11.51 & $36.26 \pm 3.58$ & 79.76 \\
\hline Gobiidae & Gobius cruentatus Gmelin, 1789 & - & 0.00 & $0.03 \pm 0.02$ & 0.79 \\
\hline Sphyraenidae & Sphyraena sphyraena (Linnaeus, 1758) & $2.68 \pm 2.68$ & 0.40 & - & 0.00 \\
\hline Mugilidae & & $6.97 \pm 3.49$ & 1.98 & $34.09 \pm 11.63$ & 7.94 \\
\hline Atherinidae & Atherina hepsetus Linnaeus, 1758 & $66.17 \pm 8.81$ & 44.05 & $55.21 \pm 11.79$ & 24.60 \\
\hline Scorpaenidae & Scorpaena notata Rafinesque, 1810 & - & 0.00 & $0.41 \pm 0.41$ & 0.40 \\
\hline & Scorpaena porcus Linnaeus, 1758 & $0.14 \pm 0.14$ & 0.40 & - & 0.00 \\
\hline & Scorpaena scrofa (Linnaeus, 1758) & - & 0.00 & $1.55 \pm 1.55$ & 0.40 \\
\hline
\end{tabular}




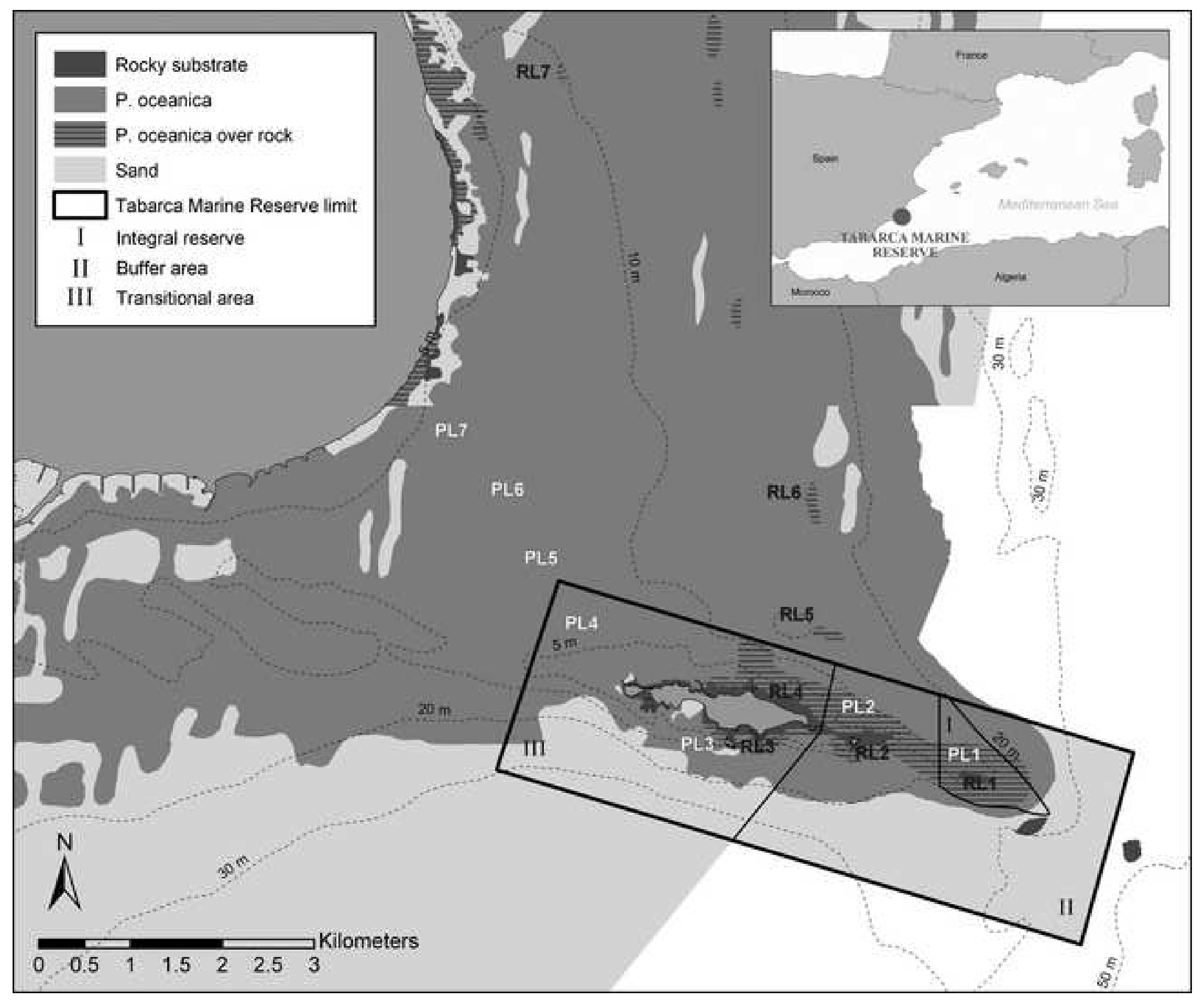

Figure 1 
a)

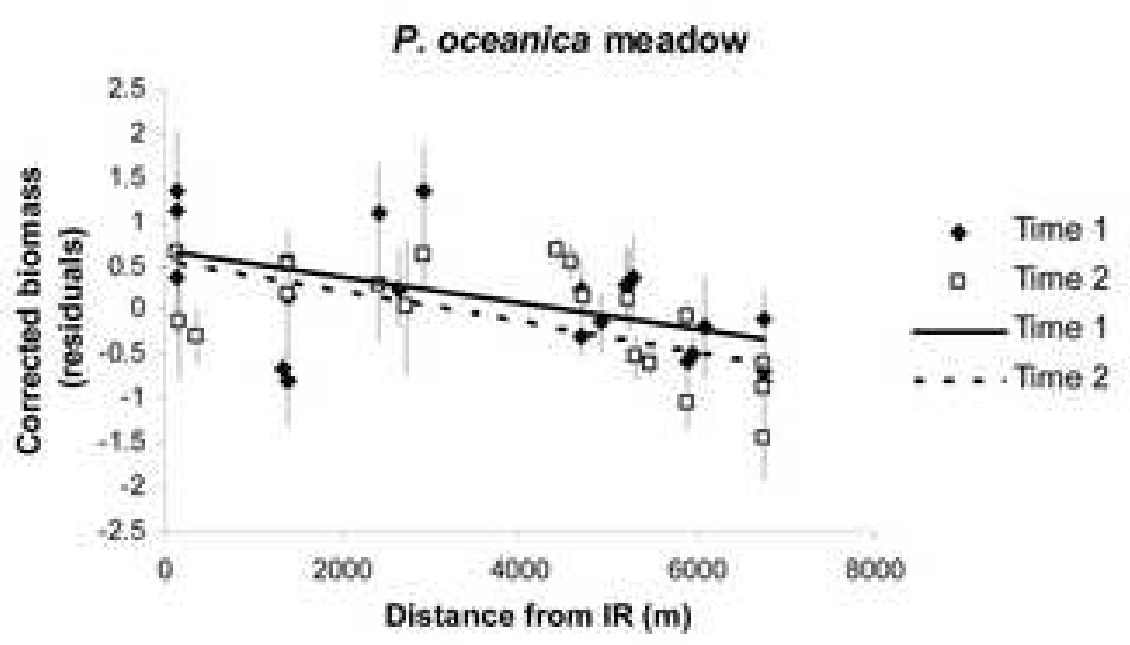

b)

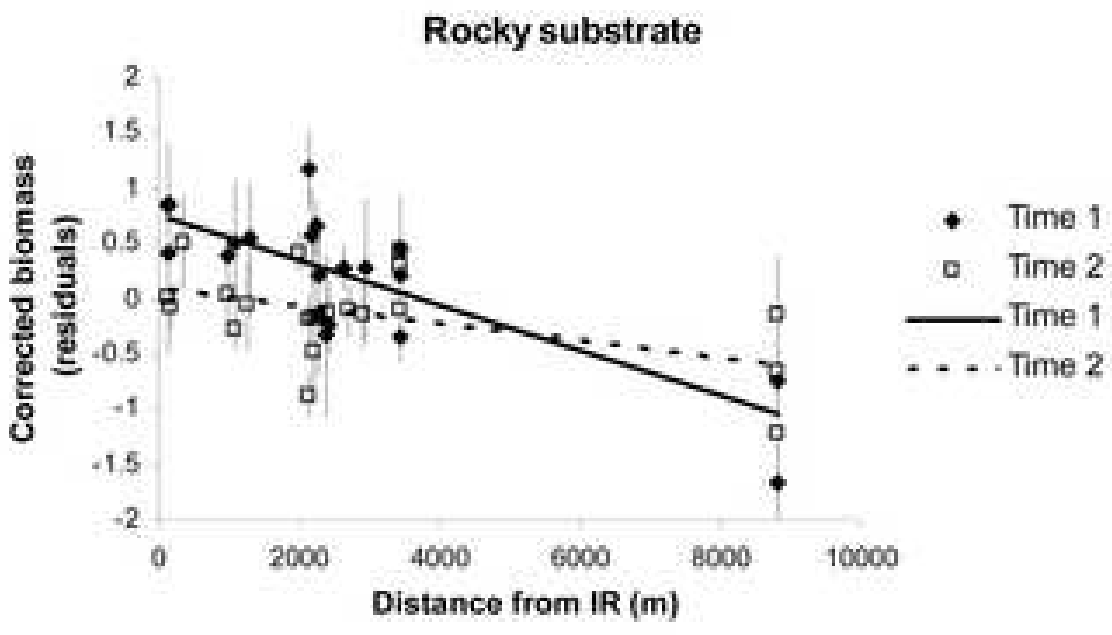

Figure 2 


\section{P. occanica meadow}

a)

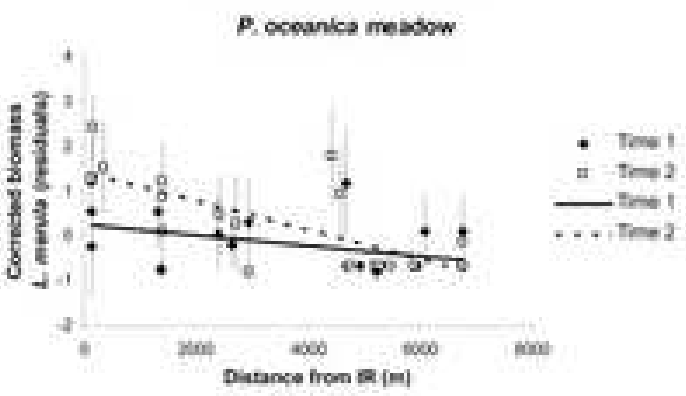

c)

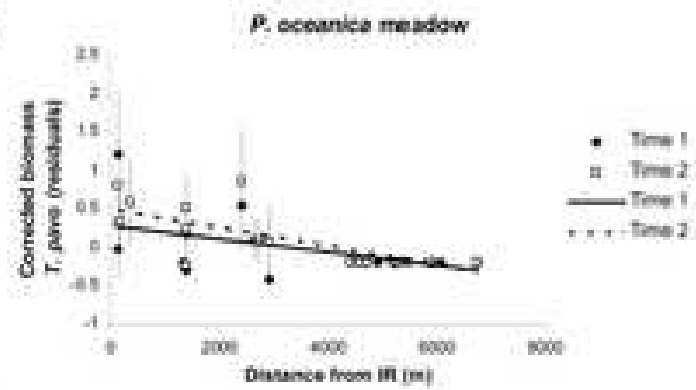

c)

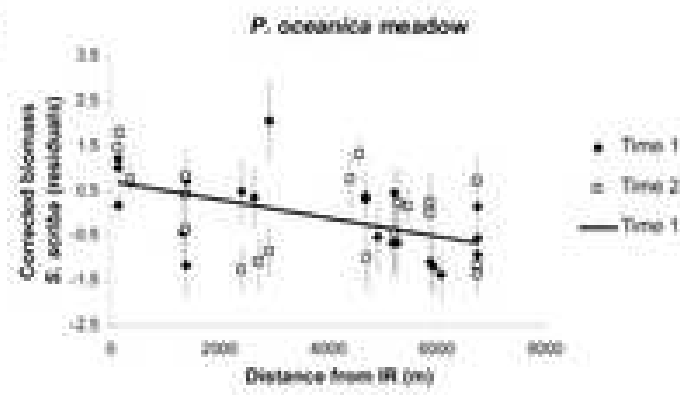

g)

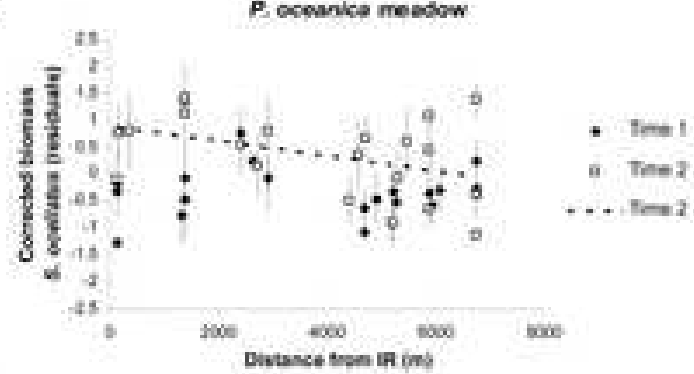

i)

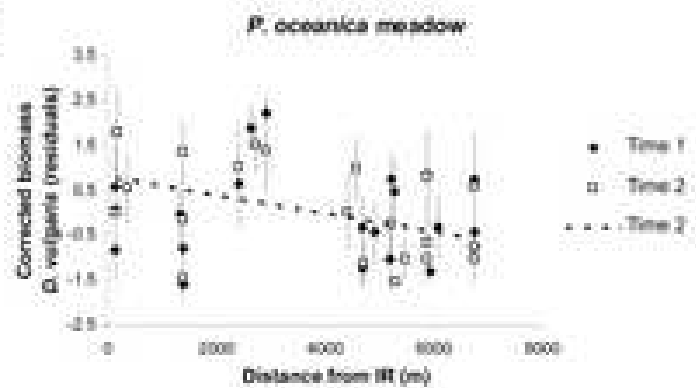

k)

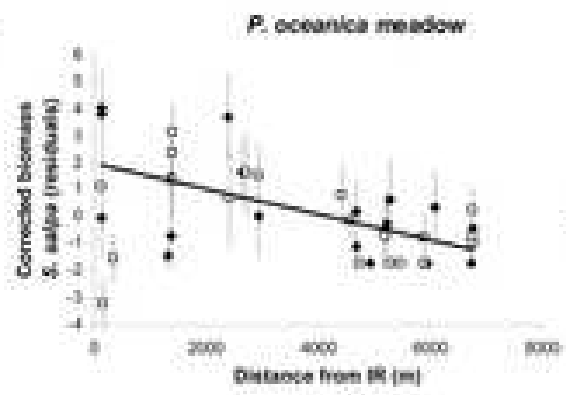

Rocky substrate

b)

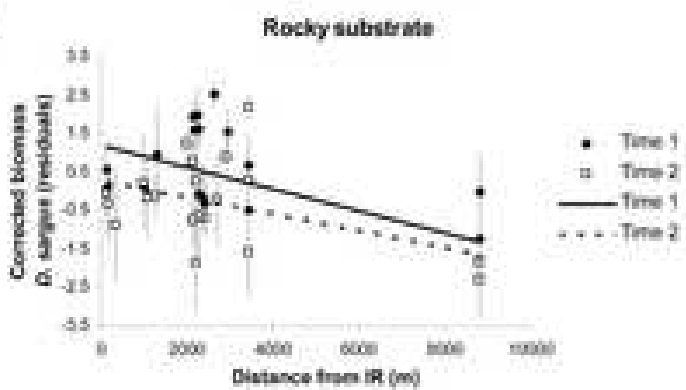

d)

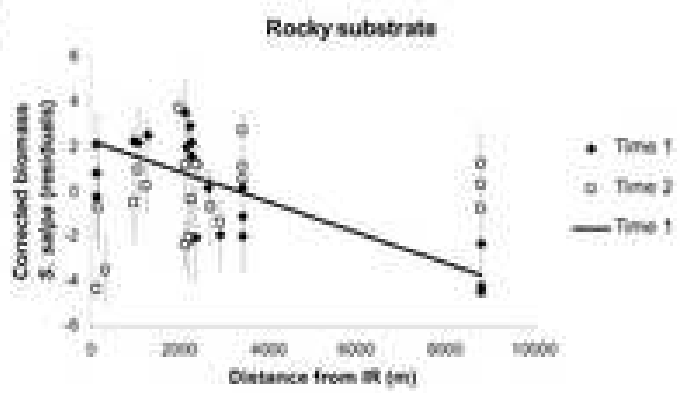

f)

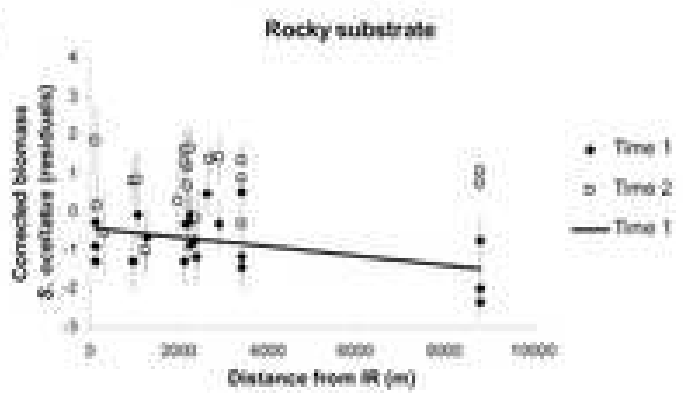

h)

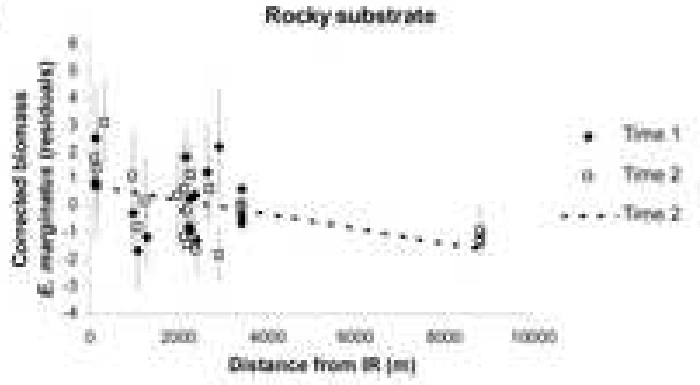

j)

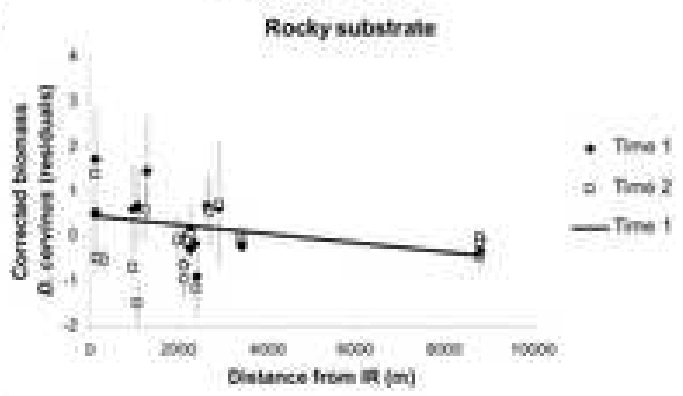

1)

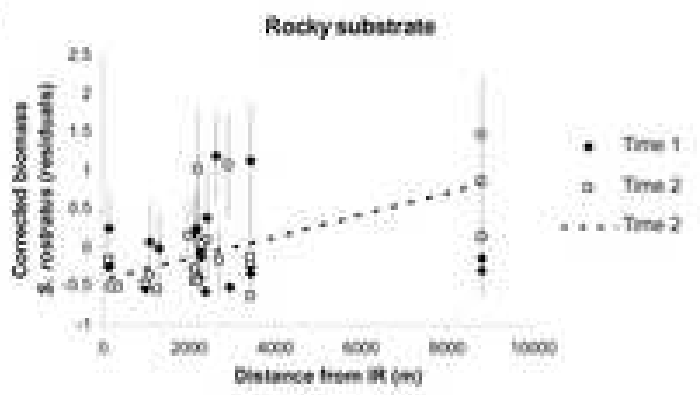

Figure 3 


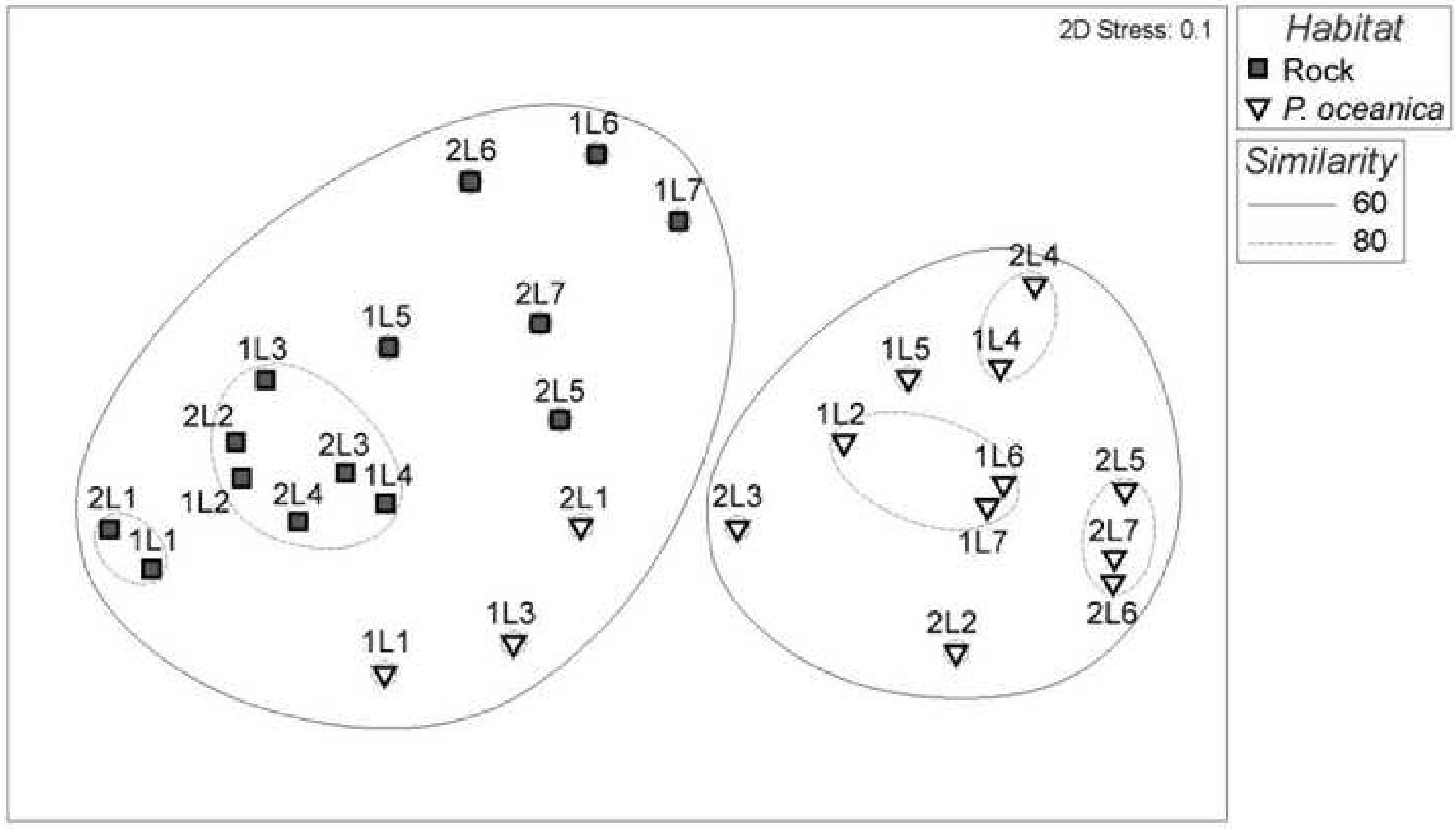

Figure 4 


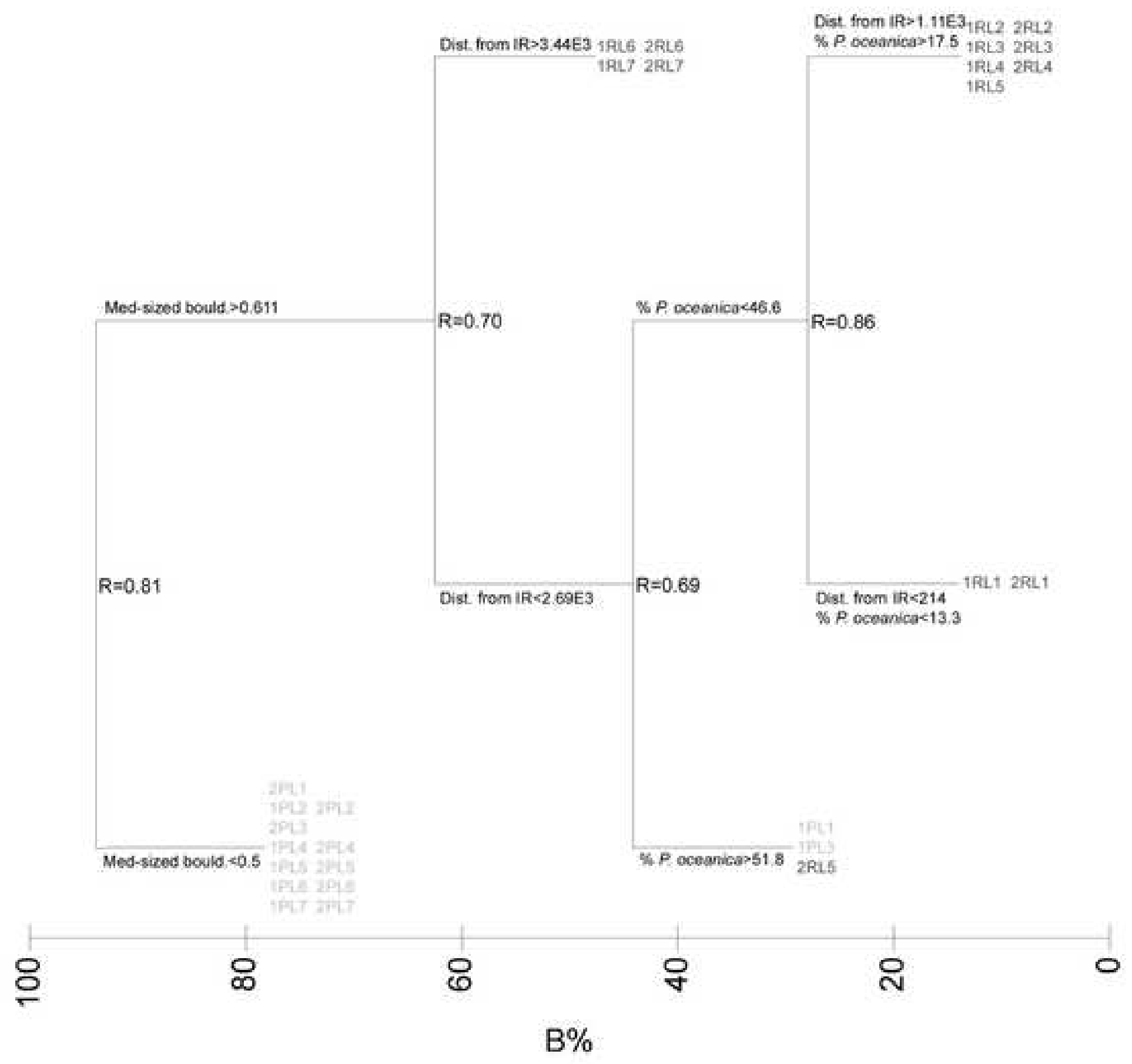

Figure 5 